\title{
Literatura y poder: \\ García Márquez en México (1961-2014)
}

Literature and power: García Márquez

in Mexico (1961-2014)

Sebastián Pineda Buitrago*

REsUmen: El objetivo de este artículo es explorar parte del contexto intelectual alrededor de la obra periodística o de no-ficción del escritor colombiano Gabriel García Márquez (19272014) a partir de su estancia en México entre 1961 y 2014. Dos preguntas se intentarán contestar en este artículo: 1) ¿iPor qué, a pesar de haber residido tanto tiempo en México, el escritor colombiano poco opinó sobre la realidad mexicana? 2) ¿Hay realmente una diferencia entre el "realismo mágico" de sus novelas y la referencialidad histórica de sus crónicas 0 artículos periodísticos?

Palabras Claves: Gabriel García Márquez, Historia intelectual, Periodismo políitico, Literatura latinoamericana

ABSTRACT: This article looks into the intellectual context of the journalistic or non-fiction writings of Gabriel García Márquez (1927-2014), those that resulted from his experiences in Mexico between 1961 and 2014. This essay will address two questions: 1) Why did Garcia Márquez not write a considerable amount of journalistic work about Mexico despite the fact that he lived such a long time in the country? 2) Is there really a difference between the "magical realism" of his novels and the historical referentiality of his newspaper articles?

Key Words: Gabriel García Márquez, Intellectual history, Political journalism, Latin American Literature.

10.22201/cialc.24486914e.2017.65.56932

Fecha de recepción:14 de mayo, 2017

Fecha de aceptación: 3 de agosto, 2017

Universidad Iberoamericana, Puebla (sebastian.pineda@iberopuebla.mx). 


\section{ELOCUENTE LACONISMO SOBRE MÉXICO}

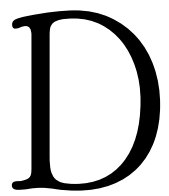

e los defectos del gran escritor hay que hablar con respeto. García Márquez conquistó al mundo con su imaginación -Cien años de soledad (1967) sigue siendo una de las novelas latinoamericanas más leídas y comentadas del mundo-, pero a sus lectores nos hubiera gustado saber qué pensaba de la realidad, del acontecer político y cultural de México, el país en el que más tiempo residió fuera de Colombia. Efectivamente, radicó en la Ciudad de México desde el 26 de junio de $1961 .{ }^{1}$ Con el tiempo construyó su casa en la zona del sur de esta ciudad, por Paseos del Pedregal, exactamente en la calle Fuego 144, donde murió el 17 de abril de 2014. Salvo una larga estancia en Barcelona entre 1968 y 1974, además de pequeñas estadías en Cartagena de Indias, La Habana, Bogotá, París y Nueva York, el escritor colombiano residió la mayor parte de su vida en la capital mexicana, pero dejó escuetos comentarios y referencias demasiado sueltas sobre su país de residencia no sólo en sus novelas y cuentos posteriores a 1960 sino, lo que todavía resulta más curioso, en su obra periodística, la escrita entre 1961 y 1995. En ella, si se revisa bien, hay opiniones sobre la situación política de Chile, Venezuela, Cuba, Nicaragua, España, Portugal, Francia y, por supuesto, Colombia, pero las que hay sobre México se limitan a pequeñas líneas. Breves impresiones. Nostalgias. ¿Por qué razón? ¿Qué le impidió a García Márquez opinar o comentar el panorama mexicano, su contexto más inmediato? ¿Acaso su relación casi íntima con el poder político?

1 Véase el dato en Gerald Martin, Gabriel García Márquez. A Life, Alfred A. Knopf, Nueva York, 2009, p. 262. Véase, en general, todo el capítulo 14, op. cit., pp. 262-285. Ahora bien, en sus memorias o autobiografía novelada, Vivir para contarla (2002), García Márquez registra que el 19 de enero de 1961 lo llamó por teléfono desde Colombia a México un capitán de un buque fluvial del río Magdalena, un tal Clímaco Conde Abello, con lo cual se entiende que ya el escritor se había radicado desde antes. (Véase Gabriel García Márquez, Vivir para contarla, México, Diana, 2010, p. 181). Sin embargo, es de notar que la autobiografía novelada del escritor colombiano se limita cronológicamente hasta 1955, año de su primer viaje a Europa, y que no trata su época en México. Por lo demás, Vivir para contarla sigue presentando, para muchos críticos, incluido el propio Martin, el tono novelístico de sus otras obras de ficción. 
Tan antigua como la misma literatura, la cercanía de los escritores con el poder político se hace especialmente interesante en el contexto hispanoamericano. En su momento, Ángel Rama discurrió en su emblemática obra, La ciudad letrada, la noción de que los intelectuales no sólo sirven a un poder, sino que son dueños de un poder. ${ }^{2}$ Rama se basó en el capítulo IV de Les mots y les choses (1966), de Michael Foucault, para insistir en que, quien maneje los signos, maneja el poder. ${ }^{3}$ Sin embargo, el crítico uruguayo no se refería tanto a los escritores propiamente dichos, como a los escribanos o burócratas de notarías o archivos públicos. Es de notar que la fijación lingüística por parte del estructuralismo de mediados del siglo XX tiene una raíz menos marxista que nietzscheana. En su libro póstumo Verdad y mentira en sentido extramoral (1903), Nietzsche relacionó el poder del lenguaje como una herramienta darwinista de supervivencia y evolución cultural. Es decir: el hombre o el grupo social que mejor mintiera -que mejor revoloteara incesantemente alrededor de la llama de la vanidad- ese, pues, dominaba a los demás. ${ }^{4}$ Pero si la verdad resulta por lo mismo inasible, no así la expresión deformada o exagerada de la realidad política y social que puede aparecer, por ejemplo, en una novela exitosa. De ahí que el crítico palestino Edward Said llegara a alarmarse de la excesiva apología al género novelístico -desde luego acrítica-, puesto que tal apología enmascara y mitifica la red que ata a los novelistas más exitosos con el Estado y con los poderes comerciales. ${ }^{5}$ Said agregó que Antonio Gramsci, mucho antes que Michael Foucault, ya había captado la idea de que la cultura sirve a la autoridad y, en última instancia, al Estado nacional, pero no porque reprima y coaccione sino porque es afirmativa, positiva y persuasiva. Lo que debemos preguntarnos, reclamaba Said, es por qué esos "grandes" novelistas silencian su realidad inme-

\footnotetext{
Cfr. Ángel Rama, La ciudad letrada, Montevideo, Arca, 1998, pp. 35 y 36.

Ibid., p. 19.

Cfr. Friedrich Nietzsche, Verdad y mentira en sentido extramoral, trad. de Luis Ml. Valdés y Teresa Orduña, Madrid, Tecnos, 1996, p. 18.

5 Edward Said, "Reflexiones sobre la crítica literaria estadounidense de "izquierda", en El mundo, el texto y el crítico, trad. de Ricardo García Pérez, Barcelona, Mondadori, 2004, p. 241.
} 
diata y por qué, a su vez, los críticos de la novela han seguido elogiando este sorprendente silencio. ${ }^{6}$

Admitamos que semejantes preguntas no nos preocuparían demasiado si no se tratara de un escritor como García Márquez, cuyos libros gozan aún de centralidad en el canon académico y comercial en cualquier repaso de la historia literaria latinoamericana de la segunda mitad del siglo xx. En vida, sin duda, ello le concedió un liderazgo de opinión o voz crítica. En este sentido, conviene incluso apoyarnos en el plano más amplio de la bistoria de las ideas (que naturalmente incluye las variaciones de bistoria cultural o bistoria intelectual) con el propósito, en última instancia, de registrar su impacto en la llamada sociología del conocimiento, esto es, en la ideología y la utopía que monopolizan una determinada sociedad. ${ }^{7}$ Hablamos de monopolio para el caso de García Márquez en cuanto a que sus libros y artículos gozaron del patrocinio de un aparato estatal y privado para formar o informar la imagen o identidad latinoamericana de las capas lectoras o cultas. En cuanto a las ideologías y utopías dominantes en Latinoamérica y especialmente en México, durante la segunda mitad del siglo xx, hay que poner, en primer lugar, el de un imaginario popular de matiz hasta cierto punto socialista o campesino, si no se olvida el afianzamiento o institucionalización de la Revolución mexicana durante el gobierno de Lázaro Cárdenas (1934-1940); testigo de ello fue el poeta Pablo Neruda, quien como cónsul general de Chile en 1940 afirmó en sus memorias, Confieso que he vivido, que la de México era "la democracia más dictatorial que pueda concebirse". ${ }^{8}$ En segundo lugar, como refuerzo de aquella ideología o utopía socialista, hay que reconocer el impacto de la Revolución cubana (1959) dentro de las clases ilustradas. Sin embargo, tal ideología y utopía son o fueron dominantes en la medida en que resultan inversamente proporcionales tanto al capitalismo acelerado como a la masificación urbana que éste trajo consigo. Por lo tanto, como uno de los

\section{Ibid., p. 234.}

Remito en este punto al clásico estudio del sociólogo alemán Karl Mannheim, Ideología y utopía. Introducción a la sociología del conocimiento, trad. de Salvador Echavarría, México, FCE, 2004, p. 43.

8 Pablo Neruda, Confieso que be vivido, Santiago, Pehuén Editores, 2005, p. 224. 
principales exponentes del boom latinoamericano y del llamado "realismo mágico", conviene preguntarse si García Márquez no fue a su vez el principal representante literario de tal ideología o utopía dominantes; alguien con buenas relaciones tanto en el mercado capitalista (sus libros se editaron y distribuyeron principalmente por editoriales comerciales) como en los regímenes de izquierda y aun en los de derecha o neoliberales, dado el divertimento de sus ficciones literarias, sin referencia a su contexto más inmediato. Como veremos, el laconismo de García Márquez sobre su cotidianidad o realidad mexicana, quizá, no obedeció a un capricho personal, sino a su fidelidad hacia el género novelístico que de alguna forma lo eximió del género ensayístico, es decir, de la crítica cultural o política.

Una primera respuesta del por qué García Márquez no dejó una narración o una reflexión a fondo sobre su vida en México, la formuló a su manera Carlos Monsiváis. Él achacó tal laconismo al artículo 33 de la Constitución mexicana:

Siempre que aquí se habla de política mexicana, García Márquez abre los
brazos y declara: "No opino nada porque soy extranjero, y me aplicarían el
artículo 33 de la Constitución de este país (que les prohíbe a los extranje-
ros inmiscuirse en la política nacional), y a Mercedes y a mí nos fastidiaría
irnos. iQué vaina!" Y uno lo oye y respeta su efecto dramático y su ironía.
Hace años, le comenté: "En política, mientras dure el PRI, todos somos ex-
tranjeros". Y me replicó sonriendo: "No se haga el ingenioso, carajo, sobre
la patria no se hacen chistes porque al que lo hace lo nacionalizan". Y se
rió.

El artículo 33 de la Constitución Política de los Estados Unidos Mexicanos, aunque con enmiendas, está en vigor desde 1829 hasta la actualidad y establece, entre varias imprecisiones jurídicas, que los extranjeros no podrán de ninguna manera inmiscuirse en los asuntos políticos del país. ${ }^{10}$

9 Carlos Monsiváis, "El mexicano", en Semana, 2 de febrero, 2007, Bogotá. En http:// www.semana.com/cultura/articulo/el-mexicano/83734-3 (fecha de consulta: 20 de marzo, 2016).

10 Véase Manuel Becerra Ramírez, "El artículo 33 constitucional en el siglo xxI", en Cuestiones Constitucionales, núm. 14, unaM, 2006. En http://biblio.juridicas.unam.mx/ libros/4/1627/7.pdf (fecha de consulta: 21 de marzo, 2015). 
Sin embargo, como veremos, García Márquez se inmiscuyó en varios de ellos. Su biógrafo más autorizado, Gerald Martin, nos cuenta que desde finales de 1987 estrechó lazos íntimos con el poder en México: "In December 1988 Carlos Salinas de Gortari became President and García Márquez moved quickly to secure his relationship with the new leader. They would work closely together on international politics during the coming years."11 Más adelante, cuando el 23 de marzo de 1994 fue asesinado Luis Donaldo Colosio en Tijuana, de acuerdo con Martin: "García Márquez broke his personal rule -and Mexico's laws- by issuing a statement on the event and calling for calm in this country he loved."12 ¿Rompió el artículo 33 de la Constitución mexicana, como quiere Martin, por ese breve comunicado de prensa? Ninguna demanda se interpuso contra él.

Tampoco hubo ninguna demanda cuando viajó el 28 de marzo de 2001, durante el sexenio de Vicente Fox, hasta la zona montañosa de Chiapas. En aquella ocasión se fotografió al lado del subcomandante Marcos, y publicó un reportaje del famoso guerrillero mexicano, con el lacónico título "Habla Marcos", en la desaparecida revista Cambio. ${ }^{13}$ No encontramos, por desdicha, un agudo análisis político. En la nota introductoria, García Márquez y su colega colombiano Roberto Pombo se limitaron a relatar, con cierta "objetividad", el efecto simbólico de la marcha que, el primero de marzo de 2001, lideró el subcomandante Marcos hacia el Zócalo de la capital mexicana. García Márquez y Pombo relataron este episodio, no obstante, con cierto aire épico y hasta apocalíptico:

En ese lugar [el Zócalo], cargado de un enorme peso histórico, el jefe del Ejército Zapatista de Liberación Nacional, sin un arma encima, hizo oficial la decisión de su movimiento de hacer política por las buenas. Desde ese día los mexicanos tienen el alma en vilo, pues saben que en buena medida el destino del país depende del éxito o del fracaso de las gestiones de este misterioso hombre encapuchado y del puñado de comandantes que

${ }_{11}$ Martin, op. cit., p. 457.

12 Ibid., p. 488.

13 García Márquez y Roberto Pombo, "Habla Marcos", en Cambio (2001/03/28). En http://www.elhistoriador.com.ar/entrevistas/m/marcos.php (fecha de consulta: 22 de mayo, 2015). 
componen su estado mayor. Su misión es lograr la aprobación de una ley de derechos para los indígenas y sentar al Gobierno de Vicente Fox, cara a cara, en una mesa de negociación. ${ }^{14}$

No deja de ser significativo que dicha marcha sucediera durante el primer gobierno panista después de la larga hegemonía del PRI. Tampoco que García Márquez y Roberto Pombo le preguntaran al subcomandante Marcos cómo veían él y los zapatistas el panorama después de la caída del PRI. Marcos respondió con evasivas y en ningún momento de la entrevista mencionó al PRI. Sus críticas las lanzó contra Fox. ${ }^{15}$ La entrevista finalizó discurriendo sobre asuntos más literarios que políticos. Por lo demás, ninguna respuesta de Marcos guarda estrecha relación con la nota introductoria -en la que se hablaba, con cierta exageración, de que el alma de los mexicanos estaba en vilo. ${ }^{16}$

En busca de referencias sobre México dentro de la obra periodística de García Márquez, sin que estas sean necesariamente políticas, nos encontramos con una de sus columnas para el diario colombiano El Espectador, con fecha del $1^{\circ}$ de junio de 1980, titulada "Algo más sobre literatura y realidad". En ella, García Márquez llegó a decir: "Sólo en México habría que escribir muchos volúmenes para expresar su realidad increíble."17 Pero, ipor qué nunca dedicó con creces un artículo, un cuento ni mucho menos una novela en donde la realidad social o política mexicana sea una referencialidad? Se nos dirá que el escenario de Cien años de soledad (1967) bien podría ser el de cualquier pueblo mexicano costero o de clima caliente, ya que Macondo es una "metáfora" de Latinoamérica. Podría ser. Pero quien rastree la gestación de Cien años de soledad advertirá que el

14 Loc. cit.

15 Loc. cit.

16 Véase un análisis de esta entrevista en Roy Krovel, "Fighting Superior Military Power in Chiapas, Mexico: Celebrity Activism and its Limitations", en Liza Tsaliki, Chistos A. Frangonikolupoulos, Asteris Huliaras, [ed.], Transnational Celebrity Activism in Global Politics. Changing the World?, Chicago, Intellect Ltd., 2011, pp. 121-140.

17 García Márquez, "Algo más sobre literatura y realidad" [publicado originalmente en El Espectador, $1^{\circ}$ de junio, 1980], en Notas de prensa. Obra periodística 5. 1961-1984, Barcelona, Mondadori, 1999, p. 154. 
escritor colombiano venía borroneando el argumento de esta novela desde sus primeros años de periodista. El 3 de junio de 1950, por ejemplo, publicó en el número 6 de la revista Crónica, editada en Barranquilla, una nota titulada "La casa de los Buendía. Apuntes para una novela". ${ }^{18}$ Por otra parte, la mención a la masacre de las bananeras en 1928 obliga a referenciar histórica y geográficamente su novela más famosa en el ámbito particular del Caribe colombiano, lejos de la realidad política de México.

En su conferencia titulada "Breves nostalgias sobre Juan Rulfo", que salió publicada originalmente el 29 de septiembre de 1980 en la revista Proceso y que ese mismo año fue recogida en el libro Juan Rulfo. Homenaje nacional (SEP-INBA, 1980), más que de Rulfo, García Márquez habló de sí mismo. ${ }^{19}$ Añadió que Álvaro Mutis le dio a leer Pedro Páramo: "-iLea esa vaina, carajo, para que aprenda! [...] El escrutinio a fondo de la obra de Juan Rulfo me dio por fin el camino que buscaba para continuar mis libros." ${ }^{20}$ Reafirma William Ospina, por otra parte, que "García Márquez supo cuál sería el tono de la más colombiana de las novelas cuando sintió el tono de la novela más mexicana." ${ }^{21}$ El tono casi fabulesco de sus recuer-

18 Durante 1950, en el diario El Heraldo de Barranquilla, García Márquez publicó tres artículos como apuntes de novela: "La hija del coronel. Apuntes para una novela" (13 de junio, 1950); "El hijo del coronel. Apuntes para una novela" (23 de julio, 1950); "El regreso de Meme. Apuntes para una novela" (22 de noviembre, 1950). Véase Fabio Rodríguez Amaya, "Crónica y ficción en Gabriel García Márquez. Fuentes de una vocación universal, 1947-1953", en Orlando Araújo Fontalvo [ed.], El legado de Macondo. Antología de ensayos críticos sobre Gabriel García Márquez, Barranquilla, Universidad del Norte, 2015, pp. 27-58.

19 García Márquez, "Breves nostalgias sobre Juan Rulfo", en Proceso, 27 de septiembre, 1980. En http://www.proceso.com.mx/129532/breves-nostalgias-sobre-juan-rulfo (fecha de consulta: 23 de abril, 2016). Véase también Juan Rulfo, Toda la obra, Claude Fell [ed.], París, Archivos, 1997, pp. 901 y 902.

${ }^{20}$ Ibid. Dicho sea de paso, el también colombiano Álvaro Mutis, contrario a García Márquez, sí relató con lujo de detalles una experiencia referencial en México: sus años de prisión en la cárcel de Lecumberri entre 1956 y 1957. La primera edición del Diario de Lecumberri apareció en la editorial de la Universidad Veracruzana, Xalapa, en 1960, con 122 páginas.

21 William Ospina, "México y Colombia", en El Espectador, 3 de septiembre, 2011. En http://www.elespectador.com/opinion/mexico-y-colombia (fecha de consulta: 25 de octubre, 2016). 
dos sobre su llegada a México se repite en su columna del 26 de enero de 1983 para El Espectador, al insistir en que ignoraba por qué, para entonces, llevaba veintiún años en la capital mexicana, "y todavía no lo sé, pero aquí estamos. Como lo dije en una memorable ocasión reciente, aquí he escrito mis libros, aquí he criado a mis hijos, aquí he sembrado mis árboles". ${ }^{22} \mathrm{El}$ origen de semejante laconismo podría entenderse mejor, como veremos, a la luz de las relaciones políticas entre el régimen del PRI y el de Fidel Castro.

\section{NuESTRO AGENTE EN LA HABANA}

Meses antes de radicarse en México, entre septiembre y diciembre de 1960, García Márquez había estado en la capital cubana como periodista de Prensa Latina. ${ }^{23}$ Masetti y Rodolfo Walsh (sus jefes inmediatos en Prensa Latina) le propusieron marcharse como corresponsal a Montreal vía Nueva York. ${ }^{24}$ García Márquez estaba bajo sospecha policial por parte de los servicios secretos de la naciente Revolución por dedicarse a la escritura novelística. ${ }^{25}$ Una vez en Nueva York, en enero de 1961, la dificultad de otro idioma, por un lado, y la fuerte oposición liderada por los exiliados cubanos contra los agentes de Prensa Latina, por el otro, lo hicieron decidirse por establecerse definitivamente en la Ciudad de México. A los cinco años de vivir allí ya había trabajado para dos agencias de publicidad estadounidenses, Walter Thompson y McCann Erickson, y para dos re-

22 García Márquez, "Regreso a México" [publicado originalmente en El Espectador, 26 de enero, 1983], en Notas de prensa 1980-1994, Bogotá, Norma, 1996, p. 467.

23 Véase, de Plinio Apuleyo Mendoza, La llama y el hielo, Bogotá,Gamma, 1989, pp. 75-77.

24 Recordemos que Masetti y Walsh descifraron los mensajes en claves de la CIA, provenientes de Nicaragua, sobre los preparativos del desembarco en Bahía Cochinos. Véase, de García Márquez, "Rodolfo Walsh, el escritor que se le adelantó a la CIA" [publicado originalmente en Alternativa, núm. 124, julio-agosto de 1977, pp. 6 y 7 , en Obra periodística 4 (1974-1995), Bogotá, Norma, 1999, pp. 177-179.

25 Dasso Saldívar, García Márquez. El viaje a la semilla. La biografía, Madrid, Alfaguara, 1997, p. 394. 
vistas comerciales o rosas, La Familia y Sucesos para Todos; ${ }^{26}$ en 1962 la editorial de la Universidad Veracruzana le había publicado Los funerales de la Mamá Grande; en 1963 la editorial Era le había hecho una reedición de El coronel no tiene quien le escriba (ya previamente publicado en Bogotá por la revista Mito, en 1958), y otra edición -la oficial- de La mala bora (1964); el 7 de julio de 1965 firmó, sin necesidad de desplazarse hasta Barcelona, un jugoso contrato con la agente catalana Carmen Balcells; por si fuera poco, el 3 de marzo de 1966, después de casi cinco años de ausencia, viajó a Colombia dentro de la delegación mexicana al viI Festival de Cine de Cartagena de Indias como guionista de una de las películas de la muestra, Tiempo de morir. ${ }^{27}$ ¿A qué obedecieron tantas bondades del ambiente cultural mexicano para un escritor colombiano recién llegado y antiguamente vinculado con Prensa Latina, la agencia de noticias de la Revolución cubana?

García Márquez no gozaba aún de la "amistad" con Fidel Castro cuando se radicó en México hacia mediados de $1961 .^{28}$ Es probable que esta "amistad" solamente se hiciera pública hasta 1975, es decir, cuando ya el colombiano era un novelista bastante famoso. Esto último invita a sospechar si tal "amistad" tenía el beneplácito de alguna instancia mexicana. El 11 de julio de 1987, como pocos intelectuales y políticos latinoamericanos, García Márquez era recibido en el Kremlin por el último presidente de la antigua Unión Soviética, Mijaíl Gorbachov, como invitado de honor al Festival de Cine de Moscú. ${ }^{29}$ Era recibido con igual soltura por Fidel Castro, sin que ello -por lo que hemos visto- le generara problemas con el régimen "democrático" o electoral monopolizado por el PRI. Parte de estos asuntos se discutieron en el debate entre Gerald Martin, el autor de

26 Ibid., p. 270. Véase el análisis de Alessandro Rocco, Gabriel García Márquez and the Cinema. Life and Works, Nueva York, Támesis, 2014, pp. 14 y 15.

27 Eligio García Márquez, Tras las claves de Melquiades. Historia de Cien años de soledad, Bogotá, Norma, 2001, pp. 68 y 69. Martin, op. cit., p. 284.

28 Castro ignoró al escritor colombiano cuando se lo presentaron por primera vez en el aeropuerto de Camagüey. Cfr. Martin, op. cit., p. 252. Véase también, de Ángel Esteban y Yamelys Aparicio, "Jodidos y octogenarios, hasta que la muerte nos repare", en Revista Hispano-Cubana, núm. 44, noviembre-diciembre. de 2012, pp. 91-112.

29 Martin, op. cit., p. 456. 
Gabriel García Márquez. A Life (2009), y el historiador mexicano Enrique Krauze. ${ }^{30}$ Éste le achacó al biógrafo británico que celebraba las loas del escritor colombiano al régimen de Fidel Castro. Por su parte, Martin lamentó que Krauze sólo se fijara en la relación (ide servidumbre?) entre García Márquez y Fidel Castro, y que pasara por alto la que tuvo el colombiano con el PRI.

Por los días de la polémica entre Krauze y Martin sobre la relación del escritor colombiano con el régimen cubano, el periodista mexicano Julio Aguilar se animó a publicar, en la edición de El Universal del 18 de octubre de 2009, el artículo titulado "La casa de Gabo era un consulado alternativo". En él, tras consultar un informe de la antigua Dirección Federal de Seguridad (DFS) en el Archivo General de la Nación, Julio Aguilar indicó que en noviembre de 1968, contrario a lo que se pensaba, el escritor colombiano sí había firmado una carta abierta solidarizándose con los presos políticos después de la represión estudiantil de Tlatelolco. ${ }^{31}$ No obstante, los informes de la DFS sobre García Márquez están llenos de contradicciones. A primera vista podría suponerse que en 1968 la DFS vigilaba las actividades del escritor colombiano, entonces también director de Habeas, una suerte de fundación que protegía y asilaba en México a militantes de la izquierda latinoamericana. La vigilancia de aquella antigua policía política, sin embargo, parecía ser bastante laxa y hasta permisiva. En su siguiente artículo, titulado "Gabo viajaba en avión enviado por Fidel", publicado el 19 de octubre de 2009 en El Universal, Julio Aguilar mencionó otro repor-

30 Gerald Martin y Enrique Krauze, "Debate a propósito de García Márquez, a la sombra del patriarca" y "Las iras del tío Jéral", en Letras Libres, noviembre de 2009. En http:// www.letraslibres.com/revista/cartas/debate-proposito-de-garcia-marquez-la-sombra-del-patriarca (fecha de consulta: 25 de abril, 2017). Antes de dicha polémica, ya la ensayista estadounidense Susan Sontag fue una de las pocas en alzar la voz, en su visita a la Feria Internacional del Libro de Bogotá en 2003, contra el silencio de García Márquez frente a los fusilamientos y recientes represiones del régimen castrista. Véase "Gabo responde a Susan Sontag", en El Tiempo, 29 de abril, 2003. En http://www. eltiempo.com/archivo/documento/Mam-1033192 (fecha de consulta: 6 de mayo, 2016).

31 Julio Aguilar, "La casa de Gabo era un consulado alternativo", en El Universal, 18 de octubre, 2009. En http://archivo.eluniversal.com.mx/cultura/60908.html (fecha de consulta: 9 de mayo, 2017). 
te del DFS, con fecha del 30 de abril de 1980, en el que parece evidente cierto beneplácito por parte del gobierno mexicano para que aterrizara sin ningún inconveniente el avión enviado por Fidel Castro. ${ }^{32}$

Semejantes informes invitan a preguntarnos qué papel, en el ajedrez político de la segunda mitad del siglo xx, jugó el escritor colombiano si parecía moverse -saltar- como un caballo entre México y La Habana. Una respuesta acertada no debería descuidar la compleja relación política entre el gobierno mexicano y el cubano. Según el historiador Mario Ojeda Gómez, en efecto, se trató de una amistad por mutua conveniencia en la que el PRI no suscribió el bloqueo estadounidense contra el régimen de Castro, con tal de que Castro excluyera a México del mapa latinoamericano de guerrillas comunistas. ${ }^{33}$ Entre las tensiones de semejante relación binacional, según Ojeda Gómez, García Márquez hizo las veces de puente o de caballo especialmente durante el gobierno de Carlos Salinas de Gortari. ${ }^{34}$

Por otra parte, no hay que olvidar las tensiones que tuvo el colombiano con Octavio Paz, entonces defensor del Estado liberal y crítico de los regímenes comunistas. Inicialmente ambos coincidieron en las páginas de la Revista Universidad de México y en las de Mundo Nuevo. Esta última se editaba en París y la había fundado en julio de 1966 el crítico uruguayo Emir Rodríguez Monegal con aparente apoyo de la CIA, dada la financiación de la Fundación Ford, como respuesta al liderazgo cultural de tendencia izquierdista de la revista cubana Casa de las Américas. ${ }^{35}$ No fue en esta última, sin embargo, donde García Márquez publicó inicialmente dos capítulos de Cien años de soledad, sino en los números de agosto de 1966 y de marzo de 1967 de la revista Mundo Nuevo. A pesar de haber

32 Aguilar, "Gabo viajaba en avión enviado por Fidel Castro", en El Universal, 10 de octubre, 2009). En http://archivo.eluniversal.com.mx/cultura/60925.html (fecha deconsulta: 19 de mayo, 2009).

33 Mario Ojeda Gómez, México y Cuba revolucionaria. Cincuenta años de relación, México, El Colegio de México, 2008, p. 106.

34 Loc. cit.

35 Véase, entre una amplia bibliografía al respecto, Jean Franco, The Decline and Fall of the Lettered City. Latin America and the Cold War, Harvard University Press, Cambridge, 2002, p. 41. Véase también, de Patrick Iber, Neither Peace nor Freedom: The Cultural Cold War in Latin America, Cambridge, Harvard University Press, 2015. 
optado por la revista de tendencia más burguesa o menos izquierdista, nadie pareció reprocharle nada a García Márquez cuando un año después estalló la polémica contra Rodríguez Monegal por los escándalos sobre el financiamiento de la CIA. Entre 1971 y 1972, a cargo de Juan Goytisolo, se intentó proseguir la empresa de Mundo Nuevo con la publicación de Libre. Revista de Crítica Literaria. Sin embargo, el caso del poeta cubano Heberto Padilla, encarcelado por el régimen castrista por su poemario Fuera del juego (Premio Julián del Casal, 1968), dividió profundamente a los intelectuales hispanoamericanos en Europa. Paz y García Márquez tuvieron posiciones distintas frente a semejante caso. El último nunca rompió con el régimen castrista ni con la revista Casa de las Américas, mientras el segundo recibió todo el financiamiento para editar en la Ciudad de México, entre 1971 y 1976, la revista Plural. ${ }^{36}$ En esta revista encontraron espacio escritores cubanos en el exilio, como Guillermo Cabrera Infante, quien arremetió contra Fidel Castro en un artículo publicado en un número de Plural de 1975, momento en que, desde otra posición cultural, García Márquez publicó una serie de artículos en la revista colombiana Alternativa, reproducidos por el diario mexicano Excélsior, en los que, como veremos más adelante, entonó alabanzas al régimen de Castro. ${ }^{37}$

Como no fuera en comentarios sueltos dejados en entrevistas y programas de prensa y televisión, la única vez que Paz polemizó abiertamente con García Márquez fue a mediados de 1975 en el número 46 de Plural, en el que publicó el artículo "Las palabras no son cosas" (pp. 78-79). En él, el mexicano le reclamó al colombiano por haber declarado su apoyo al régimen peruano bajo el Gobierno Revolucionario de la Fuerza Armada en detrimento de la expropiación de algunos medios impresos. Mientras García Márquez aplaude desde un hotel de Lisboa la decisión "revolucio-

36 Véase, de Gabriel Wolson Reyes, "Último round: la revista Plural como respuesta sintáctica a Casa de las Américas", en Iberoamericana, vol. XVI, núm. 61, 2016, p. 204. Véase también, de Jaime Perales Contreras, "Octavio Paz y el círculo de la revista Mundo Nuevo", en Estudios, núm. 102, otoño de 2012, pp. 185-193.

37 Véase una posición similar en John King, The Role of Mexico's Plural in Latin American Literary and Political Culture, From Tlatelolco to "The Philanthropic Ogre", Hampshire, Palgrave McMillan, 2007, p. 167. 
naria", según Paz, los periodistas peruanos "tienen que enfrentarse a una situación que los condena al silencio o a la lisonja del Gobierno militar. [... ¿Cómo es posible que un escritor, cualquiera que sea el partido a que pertenezca o la ideología en que se ampara hable de "manejar la información' y de servirse de ella?"’38 Por su parte, García Márquez nunca le respondió a Paz. Con éste, a pesar de la edad (Paz era 13 años mayor) y de la "ideología", lo unía un sentimiento de admiración por El laberinto de la soledad. En su novela, al fin y al cabo, García Márquez extendió al ex imperio español un fenómeno que Paz consideraba propio del mexicano, esto es, la agresiva soledad o introversión por un complejo sentimiento de "inferioridad".

Ahora bien, en contraste con México, Colombia aplicó una ruda política anti-comunista, especialmente durante el cuatrienio de Julio César Turbay Ayala (1978-1982). García Márquez buscó suavizar dicha política, pero en marzo de 1980, en una de sus numerosas estancias en Bogotá, tuvo un percance con las autoridades del gobierno colombiano. Éste, en medio de la guerra de guerrillas en el marco de la Guerra Fría, había decretado el estado de sitio. A través de uno de los editores en jefe de $E l$ Tiempo, el principal diario colombiano, se volvió pública la sospecha o acusación del gobierno colombiano contra García Márquez, a quien se le acusó de haber estado apoyando un envío de armas, a través de Cuba, para el grupo guerrillero m19. ${ }^{39}$ El 31 de marzo de 1981, en la revista Cromos, el ya famoso novelista desmintió tales acusaciones en una entrevista concedida a la periodista colombiana Margarita Vidal. García Márquez condenó el terrorismo, sí, pero sin negar su compromiso por instaurar una

38 Citado por Wolson Reyes, op. cit., p. 204. Por lo demás, en una entrevista para El País, de España, con fecha del 31 de agosto, 1990, después de la caída del Muro de Berlín, todavía Paz volvió a arremeter contra el escritor colombiano por su silencio complaciente con el régimen de Castro. Véase "Octavio Paz considera a Garcia Márquez y Carlos Fuentes apologistas de tiranos”, en El País, 31 de agosto, 1990. En https://elpais. com/diario/1990/08/31/cultura/652053604_850215.html (fecha de consulta: 30 de mayo, 2017).

39 Véase, de Rafael Santos Calderón [Ayatollah], "Viaje gratis a México", en El Tiempo, 29 de marzo, 1981, p. 5A. En http://www.revistaarcadia.com/agenda/articulo/columna-deel-tiempo-sobre-asilo-de-ggm-en-mexico/40081m (fecha de consulta: 5 de mayo, 2016). 
revolución en Colombia. ${ }^{40}$ iHasta qué punto necesitó el régimen priista asegurarse de que este escritor practicara de manera peculiar el periodismo y aun el ensayo, es decir, de que no filtrara a la prensa o a la "opinión pública" versiones a contracorriente? Para responderlo hay que analizar cómo, no necesariamente, el periodismo en García Márquez obedece a una denuncia -ni siquiera a un reflejo fiel- de la realidad.

\section{CONCLUSIONES: EL REALISMO MÁGICO}

COMO DISCURSO POLÍTICO

Antes de residir en México, García Márquez había escrito una serie de crónicas de viaje por la Alemania del Este, Polonia, Checoslovaquia, Hungría y la entonces Unión Soviética. ${ }^{41}$ En sus artículos sobre aquellos países socialistas, publicados primero en la revista Momento de Caracas, en noviembre de 1957, y luego en la revista colombiana Cromos a lo largo de 1959, García Márquez deslizó ciertas críticas contra la arquitectura soviética dejando el sinsabor de un régimen totalitario. ${ }^{42}$ Sin embargo, al destinarlas para revistas de gran consumo, sus opiniones sobre el estalinismo y la antigua Unión Soviética se diluyen en su prosa narrativa, como si en ellas él buscara la conclusión rápida, inmanente, sin demasiada trascendencia, sin cazar discusiones ideológicas alrededor del comunismo o el socialismo. La obra periodística de García Márquez no parece brotar de la

40 Véase, también Margarita Vidal, "Entrevista a García Márquez en el avión que lo llevó a México", en Cromos, núm. 3, 31 de marzo, 1981, pp. 13-17. En http://www.cromos.com.co/especial-gabriel-garcia-marquez/exilio/cromosnotaespecial-150092-garcia-marquez-quiso-mediar-entre-colombia-y-cuba (fecha de consulta: 5 de octubre, 2016).

41 Véase una crónica de este viaje en Plinio Apuleyo Mendoza, La llama y el bielo, Bogotá, Gamma, 1989, p. 21.

42 Todos los artículos al respecto están recogidos en Jacques Gilard [ed.],García Márquez, Obra periodística, vol. V, De Europa y América I [1955-1956], Bogotá, Oveja Negra, 1984, y Obra periodística vol. VI,, De Europa y América II [1957], Bogotá, Oveja Negra, 1984. 
oposición a su época ni de una tensión con su ambiente, sino que parece coincidir con el gusto de su público.

García Márquez tampoco escribió ninguna crítica contra el régimen de Fidel Castro. Al ver consolidado aquel régimen prefirió prestarle mayor atención a otros procesos de la izquierda latinoamericana, como el de Salvador Allende, sobre cuya caída publicó Chile, el golpe y los gringos (1974); o sobre el presidente panameño Omar Torrijos y su lucha por el control del Canal de Panamá, cuyo acuerdo con James Carter, en 1977, el escritor colombiano siguió de cerca; también sobre la revolución sandinista, a la que también le dedicó una crónica, "El golpe sandinista: crónica del asalto a la casa de los chanchos" (revista Alternativa, 1978). ${ }^{43}$ Este último texto, en el que relató la toma del Palacio Nacional de Managua, lo escribió sin haber estado nunca en Nicaragua, tal como lo observó el escritor nicaragüense Sergio Ramírez. ¿4́ ¿Por qué, siendo periodista, García Márquez no profundizó lo suficiente en los procesos políticos mexicanos y latinoamericanos? ¿Hay alguna razón? ${ }^{45}$

Jacques Gilard advirtió que para el análisis de la obra de ficción narrativa de García Márquez es imprescindible el de su obra de non-fiction. ${ }^{46}$ Robert L. Sims hizo un estudio pormenorizado de las alusiones, situaciones, personajes, temas, objetos, frases y metáforas de las "Jirafas", esto es, de las columnas de opinión que García Márquez publicó en los diarios de Cartagena y Barranquilla en la década de $1950 .{ }^{47}$ Sims vio cómo éstas se in-

43 Véase Rafael Rojas, "El Gabo frente a Cuba", en Nexos, vol. 36, núm. 442, $1^{\circ}$ de octubre, 2014, pp. 75-78. En http://www.nexos.com.mx/?p=22675 (fecha de consulta: 5 de octubre, 2016).

44 Véase Sergio Ramírez, "Las exageraciones de la historia", en Héctor Feliciano, Gabo periodista. Antología de textos de Gabriel García Márquez, Bogotá, Maremágnum, 2012, pp. 209-214.

45 Apuleyo Mendoza, op. cit., pp. 75-77.

46 Véase Jacques Gilard, "Prólogo", en Textos costeños. Obra periodística I, Madrid, Mondadori, 1991, p. 55.

47 Robert L. Sims, "Periodismo, ficción, espacio carnavalesco y oposiciones binarias: la creación de la infraestructura novelística de Gabriel García Márquez", en Hispania, vol. 71, marzo de 1988. En http://www.cervantesvirtual.com/obra-visor/hispania--2/ html/027e4e7a-82b2-11df-acc7-002185ce6064_20.html (fecha de consulta: 26 de mayo, 2015). 
corporan en su obra narrativa, como si no hubiera distinción entre ficción y realidad. Un artículo de García Márquez fechado en noviembre de 1950, "El chaleco de fantasía", Sims lo juzgó como un "verdadero texto-programa, un texto-umbral que nos acerca al mundo de Cien años de soledad y que logra sintetizar y equilibrar los macro elementos de la infraestructura del espacio carnavalesco". ${ }^{48}$ ¿Qué significa el espacio carnavalesco? ¿Hasta qué punto su periodismo está más cercano a la fantasía y en qué medida se aleja de la realidad?

El ejercicio periodístico de García Márquez parece sugerir la noción de que lo esencial en el periodista no es el pensamiento crítico, sino el arte de narrar a secas. Divertir, más que persuadir o convencer. Esquivar obstáculos teóricos sin cazar peleas ideológicas. Aprende a divertir -parece decirnos-: así dominarás el mundo. No es posible cerrar los ojos ante esta evidencia.

Para comprobar lo anterior conviene revisar su crónica "Cuba de cabo a rabo", que publicó originalmente en la desparecida revista bogotana Alternativa entre agosto y septiembre de 1975. Tal crónica comienza de manera similar al primer párrafo de El otoño del patriarca, la novela publicada en Barcelona por la editorial Plaza y Janés también en 1975. Ambos textos se abren con un párrafo de largo aliento, sin puntos seguidos y con el ritmo respiratorio de las comas. La crónica, en especial, comienza apelando a la verosimilitud: el autor nos asegura que él, García Márquez, ya ha visto y comprobado esa realidad y que no se trata de una utopía: "Esta realidad deslumbrante [la de 1975] no la conozco a fondo porque me la contaron, sino porque acabo de recorrer Cuba de cabo a rabo, en un viaje extenso en que nada de interés se me quedó por escudriñar." ${ }^{39} \mathrm{Un}$ escritor cubano en el destierro, Reinaldo Arenas, acusó al escritor colombiano de haber auspiciado una "izquierda festiva y fascista" ${ }^{50}$ Pero García Márquez estuvo en todo su derecho de simpatizar con quien quisiera, y

48 Loc.cit.

49 García Márquez, "Cuba de cabo a rabo" [publicada originalmente en Alternativa, agosto-septiembre de 1975], en Jacques Gilard [ed.], Obra periodística 4, Madrid, Mondadori, 1999, pp. 61 y 62 . [El subrayado es mío].

50 Véase Reinaldo Arenas, Antes que anochezca, Barcelona, Tusquets, 1998, p. 310. 
no hay nada de falso en aquella crónica periodística sobre Cuba si esa era la realidad que él percibía, estuviera o no movida por su cariño a la Revolución cubana. Además, para volver a Nietzsche, la objetividad depende del gusto estético, y éste se encuentra más allá de lo verdadero y de lo falso, de suerte que aun la ficción o el periodismo literario encierran en sí mismos una verdad. ${ }^{51}$ Esta suerte de darwinismo lingüístico, retomado por el estructuralismo de mediados del siglo xx, incluso utilizó el adjetivo anti-bumanista para oponerse a todas las formas de crítica literaria en las que el ser humano fuera el origen del significado literario. ${ }^{52}$

En este sentido, separar la calidad de la obra de García Márquez, su estética, de su ética o actividad pública, aísla y desliga su apreciación cabal. La inconexión entre ética y estética lleva a la mistificación y al aniquilamiento de los escritores. El laconismo de García Márquez en torno a la realidad mexicana, después de haberse visto rodeado de ella por más de cincuenta años, exige tanto una relectura de su obra como un revisionismo de las teorías literarias de tendencia sociológica.

51 Véase Friedrich Nietzsche, "De los poetas", en José Rafael Hernández Arias, [ed.] Así babló Zaratustra. Un libro para todos y para nadie, Gredos, Madrid, 2014, pp. 159162.

52 Véase Raman Selden, La teoría literaria contemporánea, Barcelona, Ariel, 1985, p. 11. 


\section{BIBLIOGRAFÍA}

Aguilar, Julio, "La casa de Gabo era un consulado alternativo", en El Universal, 18 de octubre, 2009. En http://archivo.eluniversal.com.mx/cultura/60908.html (fecha de consulta: el 9 de octubre, 2016).

, "Gabo viajaba en avión enviado por Fidel Castro", El Universal, 10 de octubre, 2009. En http://archivo.eluniversal.com.mx/cultura/60925.html (fecha de consulta: 9 de octubre, 2016).

, "La vida secreta de García Márquez en México", en El Universal, México, viernes, 18 de octubre, 2014. En http://www.eluniversal.com.mx/cultura/2014/la-vida-secreta-de-garcia-marquez-en-mexico-1004308.html (fecha de consulta: 20 de abril, 2015).

BECERRA RAMÍREZ, MANUEL, "El artículo 33 constitucional en el siglo XXI," en Cuestiones Constitucionales, núm. 14, unam, 2006. En http: //biblio. juridicas.unam.mx/libros/4/1627/7.pdf (fecha de consulta: 21 de marzo, 2015).

ESTEBAN, ÁNGEL, y APARICIO, YAMELYS, "Jodidos y octogenarios, hasta que la muerte nos repare", en Revista Hispano-Cubana, núm. 44, noviembre-diciembre de 2012, pp. 91-112.

FRANCO, JEAn, The Decline and Fall of the Lettered City. Latin America and the Cold War, Cambridge, Harvard University Press, 2002.

García Márquez, Eligio, Tras las claves de Melquiades. Historia de Cien años de soledad, Bogotá, Norma, 2001.

GarCía Márquez, GaBriel, "Cuba de cabo a rabo" [publicado originalmente en Alternativa, agosto-septiembre de 1975], en Jacques Gilard [ed.], Obra periodística 4 (1974-1995), Madrid, Mondadori, 1999, pp. 61 y 62.

"Rodolfo Walsch, el escritor que se le adelantó a la CIA" [publicado originalmente en Alternativa, núm. 124, julio-agosto, 1977, pp. 6 y 7], en Obra periodística 4 (1974-1995), Bogotá, Norma, 1999, pp.177-179.

, "El golpe sandinista: crónica del asalto a la casa de los chanchos" [publicado originalmente en Alternativa, núm., 178, septiembre 1978, pp. 2-10], en Por la libre. Obra periodística IV (1974-1975), Barcelona, Mondadori, 1999, pp. 205-220. 
, "Breves nostalgias sobre Juan Rulfo", en Proceso, 27 de septiembre, 1980. En http://www.proceso.com.mx/129532/brevesnostalgias-sobre-juan-rulfo (fecha de consulta: 23 de abril, 2016).

, "Algo más sobre literatura y realidad", [publicado originalmente en El Espectador, $1^{\circ}$ de junio, 1980], en Notas de prensa. Obra periodística 5. 1961-1984, Barcelona, Mondadori, 1999, pp. 154-156.

, "Regreso a México" [publicado originalmente en El Espectador, 26 de enero 1983], en Notas de prensa 1980-1994, Bogotá, Norma, 1996, pp. 465-467.

, Obra periodística vol. V, De Europa y América I [19551956], en Jacques Gilard [ed.], Bogotá, Oveja Negra, 1984.

, Obra periodística vol. VI, De Europa y América II [1957], en Jacques Gilard [ed.], Bogotá, Oveja Negra, 1984.

, "Habla Marcos", en Cambio, 28 de marzo, 2001. En http:// www.elhistoriador.com.ar/entrevistas/m/marcos.php (fecha deconsulta: 22 de mayo, 2015).

, Vivir para contarla, México, Diana, 2010.

, "Gabo responde a Susan Sontag", en El Tiempo, 29 de abril, 2003. En http://www.eltiempo.com/archivo/documento/MAM-1033192 (fecha de consulta: 6 de mayo, 2017).

GILARD, JaCQues, "Prólogo", en Textos costeños. Obra periodística I, (19481952), Madrid, Mondadori, 1991.

IBER, PATRICK, Neither Peace nor Freedom: The Cultural Cold War in Latin America, Cambridge, Harvard University Press, 2015.

KInG, JoHn, The Role of Mexico's Plural in Latin American Literary and Political Culture, From Tlatelolco to "The Philanthropic Ogre", Hampshire, Palgrave McMillan, 2007.

KRAUZE, ENRIQue, "Las iras del tío Jéral", en Letras Libres, noviembre, 2009. En http://www.letraslibres.com/revista/cartas/debate-proposito-de-garciamarquez-la-sombra-del-patriarca (fecha de consulta: 25 de abril, 2017). Krovel, Roy, "Fighting Superior Military Power in Chiapas, Mexico: Celebrity Activism and its Limitations", en Liza Tsaliki, Chistos A. Frangonikolupoulos, Asteris Huliaras [eds.], Transnational Celebrity Activism 
in Global Politics. Changing the World?, Chicago, Intellect Ltd., 2011, pp. 121-140.

MANNHEIM, KarL, Ideología y utopía. Introducción a la sociología del conocimiento, trad. de Salvador Echavarría, México, FCE, 2004.

Martin, Gerald, Gabriel García Márquez, A Life, Nueva York, Alfred A. Knopf, 2009.

, "Debate a propósito de García Márquez, a la sombra del patriarca", en Letras Libres, noviembre de 2009. En http://www.letraslibres.com/revista/cartas/debate-proposito-de-garcia-marquez-la-sombra-del-patriarca (fecha de consulta: 25 de mayo, 2015).

Mendoza, Puinio Apuleyo, La llama y el hielo, Bogotá, Gamma, 1989.

Monsiváis, Carlos, "El mexicano", en Semana, Bogotá, 2 de febrero, 2007.

En http://www.semana.com/cultura/articulo/el-mexicano/83734-3. (fecha de consulta: 20 de marzo, 2016).

Neruda, Pablo, Confieso que he vivido, Santiago, Pehuén Editores, 2005.

NIETZSCHE, FRIEDRICH, Verdad y mentira en sentido extramoral, trad. de Luis Ml. Valdés y Teresa Orduña, Madrid, Tecnos, 1996.

- Así babló Zaratustra. Un libro para todos y para nadie,

trad. y ed. de José Rafael Hernández Arias, Madrid, Gredos, 2014.

OJEDA GÓMEZ, MARIO, México y Cuba revolucionaria. Cincuenta años de relación, México, El Colegio de México, 2008.

OSpina, WiLLiam, "México y Colombia”, en El Espectador, 3 de septiembre, 2011.Enhttp://www.elespectador.comopinion/mexico-y-colombia(fecha de consulta: 25 de abril, 2016).

Perales Contreras, Jaime, "Octavio Paz y el círculo de la revista Mundo Nuevo", en Estudios, núm.102, otoño de 2012, pp. 185-193.

Pombo, Roberto y Gabriel GarCía Márquez, "Habla Marcos", en Cambio, 28 de marzo, 2001. En http://www.elhistoriador.com.ar/entrevistas/m/ marcos.php (fecha de consulta: 22 de mayo, 2015).

Rama, Ángel, La ciudad letrada, Montevideo, Arca, 1998.

Ramírez, Sergio, "Las exageraciones de la historia", en Héctor Feliciano, [ed.], Gabo periodista. Antología de textos de Gabriel García Márquez, Bogotá, Maremágnum, 2012, pp. 209-214. 
RenZ, Marlene, "Inside the Gabriel García Márquez Archive", en Cultural Compass at The Harry Ransom Center, 10 de mayo, 2015. En http:// blog.hrc.utexas.edu/2015/05/10/inside-the-gabriel-garcia-marquez-archive/ (fecha de consulta: 10 de mayo, 2016).

Rocco, Alessandro, Gabriel García Márquez and the Cinema. Life and Works, Nueva York, Támesis, 2014.

RodríGuez AmaYA, Fabio, "Crónica y ficción en Gabriel García Márquez. Fuentes de una vocación universal, 1947-1953”, en Orlando Araújo Fontalvo, [ed.], El legado de Macondo. Antología de ensayos críticos sobre Gabriel García Márquez, Barranquilla Universidad del Norte, 2015, pp. 27-58.

ROJAS, RAFAEL, "El Gabo frente a Cuba", en Nexos, vol. 36, núm. 442, $1^{\circ}$ de octubre, 2014, pp. 75-78. En http://www.nexos.com.mx/?p=22675 (fecha de consulta: 5 de mayo, 2016).

SAID, EDWARD, "Reflexiones sobre la crítica literaria estadounidense de izquierda'”, en El mundo, el texto y el crítico, trad. de Ricardo García Pérez, Barcelona, Mondadori, 2004.

SALDÍVAR, DASSO, Garcia Márquez. El viaje a la semilla. La biografía, Madrid, Alfaguara, 1997.

Santos Calderón, RAFael [Ayatollah], "Viaje gratis a México", en El Tiempo, 29 de marzo, 1981, p. 5A. En http://www.revistaarcadia.com/agenda/ articulo/columna-de-el-tiempo-sobre-asilo-de-ggm-en-mexico/40081m (fecha de consulta: 5 de mayo, 2016).

SELDEN, RAMAN, La teoría literaria contemporánea, trad. de J. G. López Guiz, Barcelona, Ariel, 1985.

Sims, ROBERT L., "Periodismo, ficción, espacio carnavalesco y oposiciones binarias: la creación de la infraestructura novelística de Gabriel García Márquez", en Hispania, vol. 71, marzo de 1988. En http://www.cervantesvirtual.com/obra-visor/hispania--2/html/027e4e7a-82b2-11dfacc7-002185ce6064_20.html. (fecha de consulta: 26 de mayo, 2015).

VIDAL, MARGARITA, "Entrevista a García Márquez en el avión que lo llevó a México", en Cromos, núm. 3, 31 de marzo, 1981, pp. 13-17. En http:// www.cromos.com.co/especial-gabriel-garcia-marquez/exilio/cro- 
mosnotaespecial-150092-garcia-marquez-quiso-mediar-entre-colombia-y-cuba (fecha de consulta: 5 de mayo, 2017).

Wolson Reyes, Gabriel, "Último round: la revista Plural como respuesta sintáctica a Casa de las Américas", en Iberoamericana vol. xVI, núm. 61, 2016, pp. 189-210. 
